\title{
RELAÇÕES DE ESTÁGIO E EDUCAÇÃO JURÍDICA NO BRASIL ${ }^{1}$
}

\author{
Isabela Fadul de Oliveira \\ Universidade Federal da Bahia (UFBA), Bahia \\ isabelafadul@gmail.com \\ Quéren Samai Moraes Santana \\ Universidade Federal da Bahia (UFBA), Bahia \\ queren_samai@hotmail.com
}

\begin{abstract}
RESUMO: O artigo está situado no marco do debate sobre educação jurídica, currículo e mundo do trabalho, e tem como objetivo refletir sobre o papel das relações de estágio no âmbito dos cursos de graduação em Direito no Brasil. Parte-se de um rápido diagnóstico sobre o estado da arte da educação jurídica, indicando seus principais avanços e desafios, especialmente no tocante à articulação entre teoria e prática. Em seguida, discute-se a relação de estágio enquanto ato educativo, em um contexto de profundas transformações e acirrado processo de precarização do trabalho em todo o mundo. Feito isto, os sentidos e significados do estágio nos cursos jurídicos são analisados com base em dois marcos normativos: as Diretrizes Curriculares Nacionais para os cursos de graduação em Direito e a Lei 11.788/2008, que regulamenta as relações de estágio no país. Ao final, procura-se evidenciar as condições de efetividade dos instrumentos normativos analisados, destacando-se o papel das instituições, órgãos e entidades no acompanhamento e fiscalização das relações de estágios jurídicos.
\end{abstract}

PALAVRAS-CHAVE: Estágio. Educação jurídica. Prática jurídica. Direito. Trabalho.

\section{The internship relations and legal education in Brazil}

ABSTRACT: The article contributes to the debates on legal education, curriculum reform and the workplace, by examining the role of internship relations in the scope of undergraduate Law courses in Brazil. The first part of the paper makes a diagnosis of the current state of legal education in Brazil, particularly its main advances and challenges. A special focus is dedicated to the articulation between theory and legal practice. The second part of the paper discusses the internship as an educational tool in a context of profound transformations in labour relations and a process of growing job insecurity worldwide. The third part of the paper analyses the meanings of the internship in legal courses, based on two normative frameworks: the National Curricular Guidelines for undergraduate courses in Law and the Law 11.788/2008, which regulates internship relations in Brazil. The final part investigates the role of the institutions in charge of regulating and overseeing the work relations of legal internships, to assess how effective the norms truly are.

KEYWORDS: Internship. Legal Education. Legal Practice. Law. Labor.

1 Este texto foi apresentado no "Sexto Congreso Internacional Sobre Enseñanza del Derecho y Tercero de Metodología de la Investigación Jurídica", ocorrido no período de 21 a 23 de novembro de 2018, na Cidade do México, e atualizado após a publicação da Portaria n ${ }^{\circ}$ 1.351, em 14 de dezembro de 2018, que homologou o Parecer CNE/CES n. 635/2018 da Câmara de Educação Superior do Conselho Nacional de Educação. 


\section{INTRODUÇÃO}

O debate sobre as condições da educação jurídica no Brasil é antigo. Desde os anos 1970 lidamos com um diagnóstico de crise que aponta para problemas de natureza múltiplas neste campo da educação superior. Tal diagnóstico foi aprofundado nos anos 1990, com o protagonismo da Ordem dos Advogados do Brasil - OAB, que liderou as discussões sobre a necessidade de mudanças nos marcos normativos que regulamentavam os cursos jurídicos no país.

Os limites metodológicos das aulas expositivas, o predomínio da visão legalista e tecnocrata nas grades curriculares, a ausência de abordagens críticas e interdisciplinares nas diversas áreas do Direito, os processos avaliativos voltados à memorização dos conteúdos ensinados e a dissociação entre teoria e prática são alguns dos aspectos desta crise duradoura. Uma crise que desafia a construção de um conhecimento capaz de compreender e transformar os complexos conflitos da contemporaneidade.

No tocante à relação teoria e prática, tivemos avanços significativos ao longo das últimas décadas, especialmente após as reformas promovidas por meio da Portaria $\mathrm{n}^{\circ} 1886$, editada pelo Ministério da Educação - MEC em 30 de dezembro de 1994 e, posteriormente, mediante a Resolução $n^{\circ}$ 09/2004 que também tratou do tema. A inserção do eixo de formação prática no currículo constituiu uma importante diretriz no sentido de minorar a tradicional desarticulação entre a teoria ensinada na sala e a realidade social em que o processo de ensino e aprendizagem está inserido. Uma realidade cada vez mais complexa e dinâmica.

O eixo de formação prática passou a prever diversas atividades, simuladas e reais, a serem desenvolvidas nos Núcleos de Prática Jurídica - NPJ, nos Estágios Curriculares Supervisionados e nas chamadas Atividades Complementares. Desde então, os Núcleos de Prática tornaram-se espaços de experiências educativas relevantes em todo o país, garantindo, sobretudo através da assistência jurídica, uma maior aproximação entre a formação jurídica e a realidade social em que esta acontece.

Já os estágios supervisionados, realizados usualmente fora das IES, permaneceram reproduzindo uma prática pouco articulada com o ensino e a pesquisa, normalmente desprovidos de um efetivo acompanhamento institucional, supervisão e avaliação pedagógica. Suas regras normalmente estão definidas nos projetos pedagógicos dos cursos espalhados pelo país e não há, seja por parte do MEC, seja da OAB, um diagnóstico claro sobre o estado da arte destas práticas.

No entanto, as relações de estágio permanecem sendo uma atividade almejada pelos estudantes desde o ingresso nos cursos superiores. As IES investem cada vez mais em parcerias e, especialmente no caso das instituições privadas, ofertam programas de estágios como importantes valores agregados aos seus produtos, buscando maiores vantagens competitivas no mercado.

Este artigo pretende refletir sobre o papel das relações de estágio no âmbito dos cursos jurídicos, considerando-as importante fator de articulação entre teoria e prática. Situamos nosso estudo face aos desafios da educação jurídica enquanto espaço de produção de um saber capaz de intervir nos atuais problemas da sociedade brasileira. Partimos do diagnóstico de crise da educação jurídica construído a partir dos anos 1970 para pensar os desafios do binômio teoria $\mathrm{x}$ prática e sinalizar os avanços obtidos nos últimos anos. Em seguida, destacamos o tema do estágio como alternativa de prática jurídica e observamos como o mesmo está previsto e regulamentado pelas Diretrizes Curriculares Nacionais. Feito isso, chamamos atenção para o problema das fraudes nas relações de estágio, muitas vezes utilizadas como forma de diminuir os custos de contratação, e analisamos a lei de estágio aprovada em 2008 com o intuito de proteger os estudantes da exploração da sua força de trabalho. 
Comparando os dois marcos normativos, concluímos pela importância de ambos no sentido de conceber o estágio como ato educativo, que integra o aprendizado e a formação do estudante o que, para o campo jurídico, significa reforçar a importância de um ensino apoiado na prática como espaço de reflexão e de produção de um conhecimento atualizado, engajado e socialmente referenciado. Por fim, apresentamos algumas considerações sobre a importância da atuação dos órgãos, conselhos e entidades de regulação e fiscalização do trabalho na proteção social dos estudantes contra a exploração da força de trabalho estudantil por intermédio dessa experiência educativa.

\section{ForMAÇÃo JURÍDICA NO BRASIL E OS DESAFIOS DA RELAÇÃo TEORIA X PRÁTICA NO PROCESSO DE APRENDIZAGEM}

O sistema educacional brasileiro tem origem em 1549 com a vinda da junta missionária jesuíta de Portugal. Após dois séculos de catequização, a coroa portuguesa instalou as reformas pombalinas, implantando o ensino laico promovido pelo Estado Português, com conteúdos baseados nas Cartas Régias e cujo público eram as elites coloniais (ARAÚJO, 2017). À época, não havia interesse de Portugal na instalação de cursos de ensino superior no Brasil e, por essa razão, durante o período colonial, o ensino superior era acessado pelas famílias de alto poder aquisitivo, que possuíam condições financeiras de enviar seus filhos a países europeus, especialmente a Portugal, onde já funcionava a Universidade de Coimbra. Algumas poucas exceções foram as escolas superiores fundadas a partir de 1808, com a chegada da família real portuguesa ao país.

Foi com a independência política do Brasil em 1822 e a necessidade de organização política-administrativa do país que o projeto de criação de cursos de ensino superior é lentamente iniciado. Os cursos de Direito foram entendidos como instrumentos de formação necessária à composição do poder político, representado pelos poderes executivo, legislativo e judiciário. Após várias tentativas frustradas, finalmente, em 1827, os primeiros cursos jurídicos foram instalados no país: a Academia de Direito de São Paulo e a Academia de Direito de Olinda (SILVA, 2019).

Ao autorizar a criação dos cursos superiores na iniciativa privada, a Constituição de 1891 inaugura um período de expansão do ensino superior no país. Com uma base curricular fechada, acessada por uma elite bem restrita da sociedade brasileira, novos cursos de Direito são criados no país. Segundo a análise de Martínez (2019), todo este período pode ser entendido como a primeira fase da evolução histórica da educação jurídica brasileiro, fundamentado no paradigma liberal, que duraria até o início do século XX.

O fato dos cursos de Direito terem se constituído por muito tempo como uma das poucas alternativas de acesso ao ensino superior talvez explique o histórico isolamento desse campo do conhecimento, muitas vezes identificado como a "ciência rainha", "em geral voltando-se aos demais ramos de conhecimento somente na medida em que importavam para o exame jurídico dos temas em debate" (NOBRE, 2019). Por muito tempo, apenas a análise da norma jurídica importava à dogmática jurídica, a qual apenas recorria a outros ramos de estudo quando era necessário utilizar o conhecimento destes como fundamentação na justificativa de seus interesses. Este isolamento, por sua vez, contribuiu para a produção e reprodução, ao longo da história, de um conhecimento muitas vezes desarticulado com a realidade social.

Em termos de currículo, uma nova matriz entra em vigor a partir de 1963, com 14 matérias obrigatórias, que comporiam o currículo mínimo e que deveriam ser cursadas ao longo de, ao menos, 5 anos de estudos. Almeja-se, a partir de então, que os cursos jurídicos contemplem as 
realidades regionais em que estão inseridos, o que garantiu alguma flexibilidade à matriz curricular. Uma década depois, o estágio supervisionado se tornaria obrigatório, como explica Krüger:

\begin{abstract}
A Resolução 3/72/CFE tornou o estágio supervisionado obrigatório, mas nem todas as instituições respeitaram. Os currículos anteriores referiam-se apenas à Prática Forense, o parágrafo único do seu artigo primeiro refere-se à Prática Forense, sob a forma de estágio supervisionado. O estágio supervisionado consiste num conjunto de atividades práticas, reais ou simuladas, voltadas ao campo de trabalho. Não obstante seu caráter prático, em grande parte dos cursos de Direito, ele é confundido com aulas expositivas. (KRÜGER, 2019 apud RODRIGUES, 1995, p. 46)
\end{abstract}

Ainda segundo o autor:

Até 1994 era previsto para os cursos de Direito, dois estágios diferenciados: (a) o estágio supervisionado (matéria do currículo mínimo, denominada de Prática Forense, sob a forma de estágio supervisionado, prevista na Resolução 3/72/CFE), de caráter obrigatório; e (b) o estágio de prática forense e organização judiciária (Lei 5842/72 e Resolução 15/73/CFE), de caráter facultativo e que uma vez cursado pelo aluno com aprovação lhe dava o direito de inscrição na OAB, independentemente da prestação do exame de ordem. (KRÜGER, 2019 apud RODRIGUES, 1995, p. 47)

A crítica à educação jurídica ganha fôlego no final dos anos $1970^{2}$, como revela a obra "Das arcadas ao bacharelismo, 150 anos de educação jurídica", de Alberto Venâncio Filho, publicada em 1977. O debate atravessa toda a década seguinte, quando a necessidade de uma nova reforma curricular vai sendo explicitada. Em 1987, Faria relatava que os cursos jurídicos se encontravam num período crise e, portanto, necessitavam de uma urgente reforma, em razão do

[...] crescente desgaste dos tradicionais mecanismos jurídicos de ordenação política, de estabilização das relações sociais e de articulação do consenso, em virtude da explosão de litigiosidade decorrente - entre outros fatores - das sucessivas crises recessivas e inflacionárias, da expansão de direitos sociais e do advento de lutas protagonizadas por grupos até recentemente sem tradição de ação coletiva de confrontação política. (FARIA, 1987)

A reforma tão aclamada do currículo destes cursos foi realizada em 1994 e possuiu como pontos de destaque a inclusão, nas diretrizes curriculares, de um eixo de formação prática "desenvolvido por meio de atividades curriculares simuladas e também reais, sob supervisão pedagógica em Núcleos de Prática Jurídica” (SOUSA JÚNIOR, 2006). Ademais das mudanças curriculares, as últimas décadas marcaram um salto significativo no tocante ao acesso aos cursos superiores do Brasil. Isto ficou ainda mais visível ao longo da década de 1990, com o aumento expressivo do número de cursos jurídicos no país, especialmente no setor privado.

Mais recentemente este contingente foi ainda mais ampliado com o aumento do número de vagas ofertadas para o ensino superior, incluindo a área jurídica, através dos programas REUNI (Programa de Apoio a Planos de Reestruturação e Expansão das Universidades Federais) e PROUNI (Programa Universidade para Todos) do governo federal.

O REUNI, por exemplo, significou um crescimento expressivo no tocante à expansão e democratização deste ingresso, através da criação de novos cursos e ampliação de vagas ofertadas em todo país, a qual alcançou um aumento de $111 \%$ entre os anos de 2003 e 2011, representando uma grande ampliação da população discente universitária (BRASIL, 2012a). Já o PROUNI ofereceu bolsas de estudo, integrais e parciais, em "instituições particulares de educação superior, em cursos de graduação e sequenciais de formação específica, a estudantes brasileiros

2 Ver em RODRIGUES, 1995; RODRIGUES, 2005; RODRIGUES, 2013; RODRIGUES, 2017; RODRIGUES; 2018 e muitos outros. 
sem diploma de nível superior"3. Isto representou um grande impacto no processo de expansão, com o financiamento pelo governo federal de novas vagas no sistema privado de ensino superior.

Os cursos jurídicos também foram afetados por essa expansão do ensino universitário no país. Atualmente, segundo os dados do Sistema e-MEC, base de dados oficial do Ministério da Educação, existem 1.423 cursos jurídicos em atividade no Brasil. Deste total, apenas 144 estão situados na rede pública de ensino e, os demais 1279 cursos estão na rede privada (BRASIL, 2012a), fato este que demonstra a expansão do ensino nos sistemas de ensino financiados de forma direta ou não pelo Estado. Segundo o Ministério da Educação, são oferecidas cerca de 220 mil vagas por ano no país (FILIZOLA, 2019). Em 2013, o Observatório do Ensino do Direito da Fundação Getúlio Vargas (GHIRARDI et al, 2014) divulgou um estudo detalhado sobre estes cursos.

Apesar da democratização do acesso aos cursos jurídicos, a grande quantidade de cursos e oferta de vagas tem sido objeto de muitas críticas e preocupações, especialmente por parte da OAB. O quadro revela uma completa ausência de projeto político educacional para a área e torna a qualidade do ensino e acompanhamento dos egressos dois grandes desafios a serem enfrentados. Mais do que nunca tem razão Junqueira quando afirma que:

\begin{abstract}
As faculdades de direito transformaram-se em fábricas de ilusões. Os alunos entram para a faculdade sonhando com a carreira de magistrado. Todos - ou quase todos querem ser juízes. No entanto, muitos ficam pelo caminho. Poucos são os efetivamente aprovados nos concursos públicos. Mesmo conhecendo essa realidade, continuamos a acenar para todos, atraindo mais alunos para nossos cursos e defendendo as possibilidades infinitas de um diploma de direito. Somos, todos nós, professores, mercadores de ilusões. Vendemos ilusões não apenas para os outros, principalmente para os estudantes, mas para nós mesmos. Ainda pior: acreditamos sinceramente nas ilusões que vendemos, o que torna mais difícil uma transformação substantiva do curso de direito. (JUNQUEIRA, 1999)
\end{abstract}

Com relação à estrutura atual dos cursos jurídicos, estes devem ser integralizados com o cumprimento de 3.700 horas aulas ao longo de, ao menos, 5 anos. Este é o período mínimo que cada aluno permanece vinculado ao curso e ao longo do qual, além de cursar as disciplinas teóricas, também realizará atividades diversas, incluído aquelas voltadas à prática jurídica.

Quanto à metodologia de ensino utilizada pela grande parte dos cursos, predominam as aulas expositivas, com assuntos apresentados de forma descontextualizada e acrítica e, muitas vezes, sem apresentar as várias visões teóricas e epistemológicas dos conteúdos. Na prática, a maioria dos cursos permanece com um

[...] ensino unidisciplinar, meramente informativo, despolitizado, massificador, adestrador e dogmático, estruturado em torno de um sistema jurídico tido como autárquico, auto-suficiente, completo, lógico e formalmente coerente ou ser uma "atividade verdadeiramente científica" eminentemente crítica e especulativa" (FARIA, 1987).

Sabe-se que o conteúdo teórico do curso de Direito é muito denso e requer o conhecimento e manuseio de teorias, princípios, legislação, jurisprudências, exigindo do aluno, além de sua compreensão e, em alguns casos, sua memorização, a capacidade de relacioná-los a casos concretos, mesmo não estando diante deles. Sobre esta situação recorrente, Oliveira afirma que:

Os ensinamentos teóricos constituem bases para o operador do direito, mas por si só são insuficientes para a formação do profissional. Por ser uma ciência social, exige contato com as pessoas, que não se adquire numa sala de aula com o método tradici-

3 BRASIL. Programa Universidade Para Todos. Disponível em: http://siteprouni.mec.gov.br/tire_suas_duvidas.php\#conhecendo. Acesso em 20 fev. 2019. 
onal de ensino, não motivador e antiestimulante da criatividade do aluno. São diretrizes que cada aluno só aprende na prática, não servindo a mera exposição de casos pelo professor, pois cada situação demanda um raciocínio e uma solução diferentes. (OLIVEIRA, 2004)

Dessa maneira, para que o bacharel em Direito possua uma formação plena, se torna indispensável um espaço em que este possa testar e aplicar os conhecimentos teóricos usualmente acessados nas salas de aula. A existência da prática jurídica, portanto, é um imperativo. Como afirmam Almeida, Souza e Camargo, "as disciplinas dogmáticas são importantes porque fundamentam o Direito positivo, mas elas sozinhas não desenvolvem o senso crítico e o raciocínio do jurista, visto que ele, quando restrito à dogmática, acaba ficando preso ao texto a lei” (ALMEIDA et al, 2013).

No entanto, "muitos discentes acreditam que as aulas expositivas e a leitura acrítica são suficientes para formar seu conhecimento, deixando de procurar outras fontes de conhecimento e de participar de atividades extracurriculares." (ALMEIDA et al, 2013). Afora isto, muitas vezes a prática existente nos cursos se resume aos exemplos trazidos para a sala de aula, os famosos "causos" contados ou "cases" trabalhados pelos professores sobre os temas abordados.

Assim como existe um amplo leque de profissões a serem seguidas por um profissional do Direito, são também várias as possibilidades atividades e vivências de prática jurídica existentes durante a graduação. A monitoria, como modalidade de prática jurídica docente, por exemplo, pode permitir que um estudante de Direito adquira conhecimentos e desenvolva habilidades essenciais à uma futura carreira docente. As atividades de extensão também podem ofertar uma gama de oportunidades e espaços de reflexão sobre a teoria e sua compatibilidade com a realidade experimentada.

Contudo, a modalidade pela qual os alunos possuem mais interesse é o estágio. Ele permite o acesso às instâncias jurídicas mais comuns, como os escritórios de advocacia e instituições públicas de Direito, vislumbrados como futuros ambientes profissionais. Apesar de previstos como atividade supervisionada a ser cursada na parte final do curso, é comum estudantes de Direito experimentarem o estágio já nos primeiros semestres do curso, de maneira informal e em atividades meramente administrativas.

O estágio também é uma forma do estudante acessar o mercado de trabalho, muitas vezes premidos pelo desemprego ou pela necessidade de, em algum momento da sua trajetória acadêmica, vender sua força de trabalho para custear-se. Assim, o autocusteio, inclusive dos estudos, pode ser considerado também como um fator que determina esta "preferência pelo estágio", visto que "os jovens no Brasil, assim como em outros países do mundo, constituem o grupo social mais escolarizado e mais desempregado, ou, mesmo, inserido em trabalhos precários" (SEGNINI, 2000). A possibilidade do recebimento de uma retribuição durante o estágio, bem como a possibilidade de conciliar o estágio com os estudos em razão da "jornada" reduzida, pode ser uma alternativa de inserção no mercado de trabalho, mesmo que de forma precária.

\section{As Diretrizes Curriculares NACIONAIS PARA A EDUCAÇÃo JURÍDICA E AS ATIVIDADES DE ESTÁGIO}

No Brasil, a educação jurídica está regulamentada pela Resolução n ${ }^{\circ} 5$, de 17 de dezembro de 2018, que institui as Diretrizes Curriculares Nacionais do Curso de Graduação em Direito a serem seguidas pelas Instituições de Ensino em todo o país. A norma, seguindo a linha da regulamentação anterior, prevê os aspectos que devem conter os Projetos Pedagógicos dos Cursos 
(PPCs), indica os atributos que devem ser assegurados ao perfil do graduando, prevê as competências mínimas a serem desenvolvidas no processo de formação profissional e determina a inclusão nos PPCs de conteúdos e atividades que atendam à formação geral, técnico-jurídica e prático-profissional, priorizando a interdisciplinaridade e a articulação de saberes.

No tocante à formação prático-profissional, o art. $5^{\circ}$, inc. III da Resolução estabelece que esta deve objetivar "a integração entre a prática e os conteúdos técnicos desenvolvidos nas demais perspectivas formativas, especialmente nas atividades relacionadas com a prática jurídica e o TC" (BRASIL, 2018). Almeja-se que as atividades de caráter prático-profissional estejam previstas no Projeto Pedagógico do Curso e atravessem as demais perspectivas formativas.

O novo marco normativo define a prática jurídica como

[...] componente curricular obrigatório, indispensável a consolidação dos desempenhos profissionais desejados, inerentes ao perfil do formando, devendo cada instituição, por seus colegiados próprios, aprovar o correspondente, regulamento, com suas diferentes modalidades de operacionalização (Art. $6^{\circ}$ ).

A Resolução $\mathrm{n}^{\circ} 5$ atribui ao NPJ a coordenação das atividades de prática. Elas podem incluir atividades simuladas e reais bem como estágios supervisionados nos termos definidos pelo PPC. A norma define ainda que o curso de graduação terá até $20 \%$ de sua carga horária destinada às atividades complementares e de prática jurídica, devendo a distribuição do percentual também estar prevista no PPC.

Assim, as novas Diretrizes Curriculares seguem a mesma estrutura da normativa anterior prevendo a Prática Jurídica como eixo estruturante dos cursos e assegurando o protagonismo do NPJ como espaço de articulação entre teoria e prática. No entanto, é mais flexível no tocante a uma das suas modalidades: o estágio supervisionado.

A normativa de 2004 admitia que uma parte da carga horária imposta ao componente curricular pudesse ser cumprida em instituições, escritórios ou serviços de assistência jurídica, mas exigia que, ao menos uma parte do Estágio, fosse realizado na própria Instituição de Ensino, através do Núcleo de Prática Jurídica:

Art. $7^{\circ}, \S 1^{\circ} \mathrm{O}$ Estágio de que trata este artigo será realizado na própria instituição, através do Núcleo de Prática Jurídica, que deverá estar estruturado e operacionalizado de acordo com regulamentação própria, aprovada pelo conselho competente, podendo, em parte, contemplar convênios com outras entidades ou instituições e escritórios de advocacia; em serviços de assistência judiciária implantados na instituição, nos órgãos do Poder Judiciário, do Ministério Público e da Defensoria Pública ou ainda em departamentos jurídicos oficiais, importando, em qualquer caso, na supervisão das atividades e na elaboração de relatórios que deverão ser encaminhados à Coordenação de Estágio das IES , para a avaliação pertinente. (BRASIL, 2004b) [Grifo nosso]

Apesar da previsão legal, acumulam-se críticas quanto ao alcance e efetivo cumprimento dessa imposição. Segundo Almeida, et al (2013):

Embora as Diretrizes impostas pelo Conselho Nacional de Educação digam que o estágio supervisionado deva ser realizado preferencialmente na instituição de ensino, e apenas subsidiariamente por meio de convênios com escritórios de advocacia e órgãos públicos (art. $7^{\circ}, \S 1$, da Resolução no 9/2004), muitos cursos jurídicos ainda se valem da opção subsidiária como sua principal estratégia de "ensino" da prática jurídica. Com isso, o ensino prático é deixado para terceiros, sem supervisão ou planejamento por parte das instituições de ensino, que cumprem uma função meramente burocrática de formalização de convênios e validação de atividades externas.

O texto legal fez surgir divergências sobre o papel da OAB nos Núcleos de Prática Jurídica, as quais levaram a Promotoria de Justiça do Ministério Público de Minas Gerais a solicitar 
mudanças a fim de dirimir as dúvidas existentes. A exposição de motivos apresentada pela Promotoria ao Ministério da Educação defende que:

\begin{abstract}
Tem havido uma incompreensão por parte da OAB, a qual acha que os NPJs (Núcleos de Prática Jurídica) têm que ser credenciados junto à mesma. No entanto, não são Núcleos de Advocacia, mas de prática jurídica (mais amplo). [...] A OAB pressiona os NPJs para que façam somente guarda, divórcio e alimentos, isto demonstra que está mais preocupada com a reserva de mercado do que com a qualidade em si do ensino e do aprendizado do aluno. No entanto, curso de ciência jurídica não forma Advogado, mas sim Bacharel em Direito. A OAB tem o critério de Exame de qualificação para selecionar os inscritos. Logo, o NPJ não precisa de (sic) credenciar junto à $\mathrm{OAB}$, da mesma forma que uma empresa que tem estagiários não precisa estar credenciada pela $\mathrm{OAB}$, basta aos estagiários inscreverem-se como tal junto à $\mathrm{OAB}$, se desejarem exercer a advocacia. (BRASIL, 2012b)
\end{abstract}

A dura crítica com relação a atuação da OAB nos Núcleos de Prática Jurídica resultou na alteração do artigo $7^{\circ}$ do texto das Diretrizes Curriculares Nacionais aprovadas em 2004. O Ministério da Educação admitiu o cumprimento da carga horária destinada ao Estágio Supervisionado fora da IES, em serviços de assistência jurídica, órgãos públicos, escritórios de advocacia e consultorias jurídicas. Com a Resolução $n^{\circ} 03$, de 14 de julho de 2017 , o $\$ 1^{\circ}$ do artigo $7^{\circ}$ das Diretrizes Curriculares Nacionais passou a vigorar com a seguinte redação:

O estágio de que trata esse artigo poderá ser realizado:

I - Na própria Instituição de Educação Superior, por meio do seu Núcleo de Prática Jurídica, que deverá estar estruturado e operacionalizado de acordo com regulamentação própria, aprovada pelo seu órgão colegiado competente, podendo ser celebrado convênio com a Defensoria Pública para prestação de assistência jurídica suplementar;

II - Em serviços de assistência jurídica de responsabilidade da Instituição de Educação Superior por ela organizados, desenvolvidos e implantados;

III - nos órgãos do Poder Judiciário, do Ministério Público, da Defensoria Pública e das Procuradorias e demais Departamentos Jurídicos Oficiais;

IV - Em escritórios e serviços de advocacia e consultorias jurídicas. (BRASIL, 2017)

A Resolução $n^{\circ} 5$ de 2018, que estabelece as atuais Diretrizes Curriculares Nacionais, adotou texto similar ao publicado pelo MEC em 2017:

Art. $6^{\circ}, \S 3^{\circ}$ A Prática Jurídica de que trata esse artigo deverá ser coordenada pelo Núcleo de Práticas Jurídicas, podendo ser realizada, além de na própria Instituição de Educação Superior:

I - em departamentos jurídicos de empresas públicas e privadas;

II - nos órgãos do Poder Judiciário, do Ministério Público, da Defensoria Pública e das Procuradorias e demais departamentos jurídicos oficiais;

III - em escritórios e serviços de advocacia e consultorias jurídicas.

Dessa forma, os Núcleos de Prática Jurídica permanecem com a importante atribuição de acompanhamento efetivo dos alunos no desenvolvimento da prática jurídica, inclusive nos casos dos estágios supervisionados. Como estes atualmente podem ser realizados integralmente fora das instalações da IES, mais do que nunca se faz importante a adoção de mecanismos de supervisão, acompanhamento e controle dessas atividades, sob pena dos Núcleos acabarem cumprindo um papel de mero intermediadores de mão de obra barata através dos contratos de estágio. 


\section{O ESTÁGIO COMO PRÁTICA JURÍDICA EM UM CONTEXTO DE PRE- CARIZAÇÃO SOCIAL DO TRABALHO}

Os dados da Associação Brasileira de Estágio, instituição criada em 2004 para promover e divulgar o estágio, revelam que existe atualmente cerca de um milhão de estagiários no país, sendo 740 mil no ensino superior (ABRES, 2019). Segundo a instituição, este total representa $5,5 \%$ apenas do total de possíveis estagiários, se considerada a soma dos estudantes dos níveis superior, médio e técnico.

Acreditando que o estágio consiste no maior instrumento de inserção do jovem no mercado de trabalho, a ABRES divulga dados de pesquisa realizada em 2017 pelo Núcleo Brasileiro de Estágios que aponta "a média geral paga aos profissionais nesta modalidade é de R\$ $1.002,79$ ”, com crescimento de 3,8\% em relação ano anterior. Entre os 25.434 estagiários entrevistados em todo o país, se considerado apenas os matriculados em nível superior, este valor chega em média a R\$ 1.125,69 (ABRES, 2019). Ainda segundo o site da instituição, o maior número de vagas oferecidas é para estudantes de Administração (16,8\%), seguidos dos estudantes de Direito $(7,3 \%)$.

Já o Centro de Integração Empresa-Escola (CIEE), associação civil de direito privado criada em 1964 com a finalidade de atuar com entidade de assistência social em programas de aprendizagem e estágio de estudantes, entende o estágio como importante mecanismo de acesso e integração do mundo do trabalho. Seu programa de estágio possui 15 mil instituições de ensino associadas e milhares de empresas e organizações públicas parceiras, e há décadas vem cumprindo um papel relevante como "agente integrador" e mediador dos vínculos de estágio. O relatório de atividades da instituição "Balanço Social 2017" indica a ampliação de vagas de estágios que, em 2017, culminaram no total de 234.868 novos estagiários contratados (CIEE, 2019).

Se relacionarmos esse aumento significativo de vínculos de estágio no mercado com o crescimento do número de cursos e matrículas no ensino superior brasileiro, percebemos que a tendência é de que essas relações se consolidem como um importante espaço de acesso ou experimentação do jovem no mercado de trabalho. Dado ao crescimento dos cursos e número de matrículas no Direito, esta área acaba se constituindo em um caso paradigmático.

Ao agregamos a este quadro um contexto de baixo crescimento econômico e a necessidade de os jovens venderem sua força de trabalho para garantir sua subsistência, temos um contexto de extrema vulnerabilidade dos educandos. Especialmente daqueles em idade avançada, normalmente vinculados ao ensino superior, que buscam o estágio primordialmente como fonte de renda.

Esta expectativa juvenil muitas vezes é reconhecida e incentivada nas ações governamentais e suas políticas públicas voltadas para as áreas de juventude, educação e trabalho. Segundo o Parecer do Conselho Nacional da Educação que versou sobre as normas de organização e realização de estágio de alunos do Ensino Médio e da Educação Profissional,

[...] na realidade, o estágio supervisionado propicia o aluno a oportunidade de qualificação prática, pela experiência no exercício profissional ou social, acompanhado e supervisionado profissionalmente, o que torna uma atividade facilitadora da obtenção de um trabalho, na maior parte das vezes do "primeiro emprego". (BRASIL, 2003)

Uma preocupação que este quadro sugere, principalmente levando em conta a tendência crescente de flexibilidade na contratação da força de trabalho, é a possibilidade de os vínculos 
de estágios acabarem por camuflar verdadeiras relações de assalariamento. As denúncias de burlas ao Ministério Público do Trabalho e os casos de reconhecimento de vínculo empregatício em relações disfarçadas de estágio pela Justiça do Trabalho indicam essa tendência.

Os estudos de Mesquita (2011) sobre a luta de estagiários paulistas contra situações de desvirtuamento das relações de estágio e de Coelho (2011) sobre os conflitos envolvendo relações de estágios levados a Justiça do Trabalho do Estado da Bahia entre os anos de 2007 e 2010 apontam nesta direção. Neste último caso, a pesquisa revela que de 682 processos de estágio que tramitam no TRT da 5a Região, 509 tiveram decisões considerando que o contrato de estágio fora desvirtuado (COELHO, 2011).

Ao tratar da possibilidade de o estágio constituir uma relação de emprego disfarçada e mais um instrumento de reforço a lógica da flexibilização da forma de contratação da força de trabalho, Krein alerta que para os jovens, o estágio "é uma esperança de aquisição de experiência profissional e inserção no mercado de trabalho. Isso faz com que, apesar da precariedade, haja uma disputa acirrada pelas vagas que surgem" (KREIN, 2013).

O desvirtuamento da finalidade do estágio acontece de diversas formas: prática de atividades que não possuem relação com sua área de formação, submissão a rigorosos controles de horas trabalhadas, realização de horas extras, ausência de acompanhamentos ou supervisão de suas atividades, excesso de responsabilidades (inclusive sobre outros trabalhadores). Muitas vezes é evidente a indispensabilidade do estagiário ao serviço ou à realização da produção.

Em estudo recente sobre os estágios jurídicos, Castro (2016) aponta inúmeras irregularidades em estágios no próprio campo trabalhista, especialmente nos escritórios de advocacia, em que a finalidade pedagógica do estágio foi desvirtuada por inúmero motivos como: apresentar objetivo produtivo, se localizar na etapa de produção, objetivar a diminuição da carga de trabalho de profissionais do quadro efetivo, ter função especifica a ser desempenhada, ser essencial ao tomador dos serviços ou até ser utilizado como substituição de mão de obra.

Também é comum encontrar anúncios indicando a experiência desejada e o grau mínimo de escolaridade (no caso, o semestre em que se encontra o estudante no curso), semelhanças entre processos seletivos para a contratação de estagiários e para a contratação de empregados, padrões semelhantes de remuneração e contagem do tempo de trabalho etc. Foi com o propósito de enfrentar e combater esse quadro de exploração da força de trabalho juvenil nas relações de estágio que foi editada a Lei 11.788/2008.

\section{A LEI de ESTÁGIO E A PROTEÇÃo SOCIAL AO ESTUdANTE}

A chamada "nova lei de estágio" foi instituída com o objetivo de coibir a ampliação da precarização do trabalho por intermédio das relações de estágio. Este foi o maior propósito da Lei 11.788, em vigor desde 25 de setembro de 2008: evitar as distorções do contrato de estágio como mecanismo de redução de custos com a força de trabalho subordinada. Ao menos, é o que anuncia sua exposição de motivos:

\footnotetext{
Nesse panorama, atentos a que a legislação que regula a realização de estágio data de 1977, apresentando graves anacronismos, não obstante tenha sofrido alterações em sua redação nos últimos anos, estamos propondo o presente projeto que cuida da matéria de maneira mais sistematizada, visando a que o estágio possa desenvolver-se sem desvirtuações, cumprindo o papel de agende no desenvolvimento do educando, preparando-o no exercício da cidadania e na sua qualificação para o trabalho (BRASIL, 2008).
} 
Ainda de acordo com a exposição de motivos da lei, o estágio é uma oportunidade de o educando ter contato com o mundo do trabalho, ampliar sua formação acadêmica e não evadir da escola, "na medida em que proporciona a efetiva vivencia profissional, concretizando os conteúdos teóricos apreendidos no mundo acadêmico" (BRASIL, 2008). Ao aliar frequência escolar e trabalho, o estágio é visto como

[...] um instrumento eficaz no combate ao desemprego dos jovens, pois, quando tenham que disputar uma vaga no mercado de trabalho formal, possuirão, aqueles que passaram por programas de estágio, um melhor nível de instrução, bem como experiência e vivência interativa no mundo do trabalho (BRASIL, 2008).

Segundo o art. $1^{\circ}$ da Lei 11.788, o estágio é um ato educativo escolar supervisionado que, apesar de envolver a energia humana produtiva em atividades controlada, dentro de um determinado período de atividade e muitas vezes remunerada, não configura relação de emprego. É o que alerta $\mathrm{o}$ art. $3^{\circ}$ da mesma norma.

O estágio é regulamentado como um vínculo triangulado entre a instituição de ensino, o estudante e a parte concedente do estágio, com direitos e deveres bem definidos para cada uma das partes. Permite-se ainda que agentes de integração possam mediar essa relação, a fim de auxiliar o processo de contratação e supervisão do estágio, atividades há décadas realizadas por instituições como o CIEE e o IEL (Instituto Euvaldo Lodi).

O contrato de estágio se torna válido formalmente mediante a existência de um Termo de Compromisso que deve ser adequado ao Projeto Pedagógico, bem como à etapa e modalidade da formação escolar do curso. O termo deve conter as assinaturas de todos os envolvidos e a ele deve ser anexado o plano de atividades do estudante, as quais devem ser compatíveis com a natureza do curso. No tocante à parte concedente, esta poderá ser Pessoa Jurídica de Direito Público ou Privado, bem como profissional liberal que deverá possuir um mínimo de empregados exigido para a contratação de estagiários, obedecendo porcentagem estabelecida pela Lei.

São requisitos indispensáveis ao vínculo: matrícula, frequência e compatibilidade entre as atividades de estágio e a área de formação do estudante, sob pena de configuração da relação de emprego. Aqui reside uma das principais medidas da nova normativa para impedir as fraudes nas relações de trabalho: a compatibilidade entre a atividades desenvolvidas no estágio e a área de formação do estagiário.

No tocante à duração dos vínculos e das atividades, a nova lei limita a carga horária de estágio no ensino superior em seis horas diárias, respeitando o máximo de trinta horas semanais, resguardada a meia jornada nos períodos de provas. Quanto à duração do vínculo, este fica limitado a dois anos de duração na mesma instituição concedente. Sem dúvidas, os critérios temporais seguem à lógica adotados até então pela legislação celetista no tocante aos contratos de emprego por tempo determinado.

Outra inovação legislativa é a classificação dos estágios em obrigatórios e não obrigatórios, conforme definição do projeto pedagógico do curso. A lei descreve ambas as modalidades:

Art. $2^{\circ} \mathrm{O}$ estágio poderá ser obrigatório ou não-obrigatório, conforme determinação das diretrizes curriculares da etapa, modalidade e área de ensino e do projeto pedagógico do curso.

$\S 1^{\circ}$ Estágio obrigatório é aquele definido como tal no projeto do curso, cuja carga horária é requisito para aprovação e obtenção de diploma.

$\S 2^{\circ}$ Estágio não-obrigatório é aquele desenvolvido como atividade opcional, acrescida à carga horária regular e obrigatória. (BRASIL, 2008) 
Tal diferenciação é relevante no tocante à obrigatoriedade de concessão de bolsa ou outra forma de contraprestação, a qual somente é prevista no caso dos estágios não obrigatórios ${ }^{4}$. A lei não define o valor mínimo desta contraprestação, ficando a imposição do pagamento vinculada à previsão do caráter obrigatório do estágio no PPC de cada IES.

Aspecto também importante da nova lei de estágio é o fato da mesma assegurar ao estagiário um período de recesso de 30 dias, sempre que o estágio tenha duração igual ou superior a um ano, a ser gozado, de preferência, durante as férias escolares. A lei anterior não tratava do assunto.

Além de tratar da duração dos contratos, jornada e formas de contraprestação, a Lei 11.788 garante ao estágio um seguro contra acidente e estabelece limites ao número de contratações a depender do número de empregados na empresa, podendo chegar a $20 \%$ de estagiários nas empresas com mais de 25 empregados.

Com relação às obrigações quanto a supervisão e acompanhamento do estágio, a lei define atribuições concretas tanto às instituições concedentes, quanto às instituições de ensino. Cabe às primeiras designarem um funcionário do seu quadro para orientar e supervisionar as atividades de no máximo dez estagiários simultaneamente, cujas atividades devem ser registradas em relatórios semestrais enviados às IES. Às instituições de ensino cabem o maior caráter fiscalizatório, pois são responsáveis pela análise da compatibilidade das atividades realizadas pelo estagiário com o previsto nos termos de compromisso e a natureza do curso.

Além disso, as instituições deverão avaliar as condições em que os estágios estão acontecendo (como infraestrutura, por exemplo) e indicar professor orientador para realizar supervisão do estagiário. Ao estabelecer estas condições e garantias, a nova lei de estágio pretendeu assegurar o caráter educativo do estágio e proteger o estudante do uso abusivo da sua força de trabalho.

\section{AS CONDIÇÕES DE EFETIVIDADE DOS MARCOS NORMATIVOS}

Ao cotejarmos os dois marcos normativos analisados anteriormente, percebemos seus diversos pontos de convergências e a importância de ambos na regulação da prática jurídica no atual momento da educação jurídica do país.

Um primeiro aspecto a ser destacado diz respeito a natureza do estágio, concebido por ambos como ato educativo, necessário à formação jurídica e, portanto, como vivência que antecede a vida profissional. O estágio, neste caso, é entendido como eixo formativo integrado ao aporte teórico, e a ele indissociável.

Assim como a Lei de Estágio define o estágio como um ato educativo, as Diretrizes Curriculares o tratam como componente obrigatório dos cursos de direito, reafirmando o papel pedagógico deste instrumento na formação dos profissionais do direito. Ambos caracterizam o estágio como ato supervisionado, de forma que as Diretrizes Curriculares utilizam o termo "Estágio Supervisionado" para o definir, excluindo assim qualquer outra forma de relação de estágio. Dessa maneira evidencia uma preocupação com o possível desvirtuamento do estágio e indica a supervisão como o mecanismo apto a evitá-lo.

Um segundo aspecto que merece destaque refere-se à importância da proteção ao estudante de Direito em um momento de expansão da educação jurídica. O aumento da oferta de

4 “Art. 12. O estagiário poderá receber bolsa ou outra forma de contraprestação que venha a ser acordada, sendo compulsória a sua concessão, bem como a do auxílio-transporte, na hipótese de estágio não obrigatório.” (BRASIL, 2008) 
força de trabalho especializada no mercado de trabalho, atrelado ao atual contexto de crise econômica e aumento do desemprego no país requer uma legislação que proíba a utilização dos vínculos de estágio como mão-de-obra barata. Aqui os mecanismos de acompanhamento previstos na Lei de estágio, impostos às Instituições de Ensino e às empresas e instituições concedentes do estágio são de suma importância. No caso dos cursos de Direito, soma-se a Ordem dos Advogados e os órgãos públicos em geral.

Outro ponto de aproximação entre as legislações é a assimilação de que o estágio é um espaço de preparação para o exercício da profissão jurídica e, dessa forma, o aluno não poderá realizar atividades que não estejam relacionadas com o seu curso. Neste aspecto, a supervisão do estágio também é de grande importância.

No caso dos cursos jurídicos, esta supervisão pode ser entendida como um grande desafio, visto a existência hoje de mais de 1,1 milhão de advogados no país (ORDEM DOS ADVOGADOS DO BRASIL, 2019), número este que reflete na grande quantidade de escritórios de advocacia existentes, bem como o grande contingente de instituições públicas e privadas que recebem estagiários no âmbito das suas atividades.

Ainda que os dois marcos normativos tenham pontos importantes de aproximação e não entrem em contradição, a garantia das condições de efetividade de ambos depende da atuação das instituições envolvidas na verificação da efetiva supervisão das atividades de estágio e de mecanismos que evitem a sua descaracterização.

A criação de um requisito que vede a realização de estágios fora da IES, sem a comprovação da existência de um mecanismo efetivo de supervisão por parte dos entes envolvidos, poderia ser um fator que facilitaria este acompanhamento e garantiria a qualidade dos estágios realizados, bem como o não desvirtuamento das suas finalidades educativas.

Outro mecanismo de acompanhamento possível de ser adotado seria a criação de componentes curriculares a serem cursados pelos alunos durante a vigência do contrato de estágio, em que os estagiários, em constante contato com um supervisor acadêmico, poderiam trocar experiências e refletir não apenas sobre o resultado da aplicação prática dos conhecimentos jurídicos mas também sobre as condições de trabalho dos profissionais da área, seja com o professor encarregado do componente curricular, seja dos demais estudantes inscritos. Garante-se assim que a prática alimente a teoria fechando, de forma virtuosa, o círculo teoria-prática-teoria na construção de um conhecimento novo e atualizado, ao tempo em que se aguça o olhar crítico dos estudantes para o mundo do trabalho que os aguardam.

Por fim, os órgãos de fiscalização do mundo do trabalho podem também cooperar na fiscalização das práticas de estágio, a exemplo do Ministério do Trabalho e o Ministério Público do Trabalho, que possuem a competência de fiscalizar e punir empresas que façam uso irregular da força de trabalho. As entidades de classe e sindicatos também podem ter um papel relevante na supervisão das relações de estágio, um tema tão ausente das suas agendas de trabalho.

\section{CONSIDERAÇÕES FINAIS}

Os desafios de articular teoria e prática, assim como pensar a relação educação-trabalho, toca aos mais diversos campos do conhecimento e o Direito não foge à regra. Esta é uma tarefa inacabada, mas necessária. A articulação entre prática e teoria, ao mesmo tempo em que possibilita avançar na promoção de uma formação jurídica com condições de responder à complexidade das questões sociais contemporâneas, cria condições para a formação de profissionais melhor qualificados para ingressar e ofertar sua força de trabalho no mercado. 
Neste contexto, as atividades de estágios jurídicos podem significar importantes espaços da produção de um conhecimento contextualizado, crítico e socialmente referenciado. Os marcos normativos que hoje regulamentam a matéria do Brasil apontam avanços pois sinalizam a importância de garantir uma proteção social do estagiário contra a exploração da sua força de trabalho e de preserva o sentido de ato educativo das relações de estágio, visando que estas signifiquem efetivamente a complementação da formação profissional dos educandos.

As diretrizes nacionais para a educação jurídica concebem o estágio como modalidade de prática jurídica, entendendo-a como elemento estruturante da formação na área, ainda que a tendência apontada recentemente seja a de reconhecer a possibilidade de que toda a experiência de prática jurídica seja realizada fora da IES. Ao mesmo tempo, conta-se com uma legislação trabalhista que concebe o estágio como um ato educativo e amplia os deveres e responsabilidades das instituições de ensino e entidades concedentes, ainda que em muitos momentos utilize como paradigma a relação de emprego para regular as condições de execução do estágio.

A convergência entre os conteúdos dos dispositivos normativos são indicativos importantes para a garantia da natureza educativa do estágio. No entanto, a efetividade desses marcos normativos dependerá da atuação das entidades imbuídas do acompanhamento e fiscalização desses vínculos, à luz do debate mais amplo sobre a educação para o trabalho no Brasil.

Afora as responsabilidades atribuídas às instituições de ensino e instituições concedentes dos estágios, os órgãos púbicos de regulação do trabalho, bem como as entidades estudantis e sindicais, podem jogar um papel importante no acompanhamento e fiscalização desses vínculos. Ampliar este debate para além da academia talvez seja a grande tarefa a ser perseguida.

\section{REFERÊNCIAS}

ABRES. Estatísticas. Disponível em: http://www.abres.org.br/v01/dados-estagiarios-estudantes-no-brasil/. Acesso em: 21 fev. 2019.

ALMEIDA, Frederico de. et al (Coord.). Direito e realidade: Desafios para o ensino jurídico. Ensino do direito em debate: reflexões a partir do $1^{\circ}$ Seminário Educação jurídica e Formação Docente. São Paulo: Direito GV, 2013.

ARAÚJO, Marciano Vieira de. A Evolução do Sistema Educacional Brasileiro e seus Retrocessos. Revista Científica Multidisciplinar Núcleo do Conhecimento. São Paulo, ano 2, vol. 1, p. 52-62, abr. de 2017.

BRASIL. Análise sobre a Expansão das Universidades Federais 2003 a 2012. Brasília: Ministério da Educação, 2012a.

BRASIL. Lei $\mathrm{n}^{\circ} 11.788$, de 25 de setembro de 2008. Dispõe sobre o estágio de estudantes. Diário Oficial [da] República Federativa do Brasil, Poder Executivo, Brasília, DF, 26 set. 2008.

BRASIL. Parecer CNE/CEB no: 35/2003, de 05 de novembro de 2003. Normas para a organização e realização de estágio de alunos do Ensino Médio e da Educação Profissional. Diário Oficial [da] República Federativa do Brasil, Brasília, DF, 20 jan. 2004a.

BRASIL. Parecer CNE/CES nº: 362/2011, de 01 de setembro de 2011. Solicitação para que seja verificada a possibilidade de se aperfeiçoar a redação do art. $7^{\circ}, \S 1^{\circ}$, da Resolução CNE/CES n ${ }^{\circ}$ 9/2004, que trata dos núcleos de prática jurídica. Diário Oficial [da] República Federativa do Brasil, Brasília, DF, 30 maio. 2012b. Seção 1, p. 33. 
BRASIL. Resolução CNE/CES no: 09/2004, de 29 de setembro de 2004. Institui as Diretrizes Curriculares Nacionais do Curso de Graduação em Direito e dá outras providências. Diário Oficial [da] República Federativa do Brasil, Brasília, DF, 29 set. 2004 b.

BRASIL. Resolução no: 03/2017, de 14 de julho de 2017. Altera o Art. $7^{\circ}$ da Resolução CNE/ CES nº 9/2004, que institui as Diretrizes Curriculares Nacionais do Curso de Graduação em Direito. Diário Oficial [da] República Federativa do Brasil, Brasília, DF, 17 jul. 2017. Seção 1. p. 12.

BRASIL. Resolução no: 635/2018, de 04 de outubro de 2018. Institui as Diretrizes Curriculares Nacionais do Curso de Graduação em Direito e dá outras providências. Diário Oficial [da] República Federativa do Brasil, Brasília, DF, 17 dez. 2018. Seção 1. p. 34.

CASTRO, Lucas Santos de. A finalidade pedagógica do estágio: uma análise do (des)cumprimento dos requisitos da lei ${ }^{\circ}$ 11.788/2008 nos estágios jurídicos na área trabalhista em Salvador. Salvador: Universidade Federal da Bahia, 2016. $135 \mathrm{f}$.

CIEE. Relatório de Atividades CIEE. Balanço Social 2017. Disponível em: http:// www.ciee.org.br/portal/biblioteca-digital/content/balanco/online/2017/Relatorio_de_Atividades_CIEE_2017.pdf. Acesso em: 21 fev. 2019.

DRUCK, Graça. A precarização social do trabalho no Brasil: alguns indicadores, Riqueza e miséria do trabalho no Brasil. São Paulo: Boitempo Editorial, 2013.

FARIA, José Eduardo. A reforma do Ensino jurídico. Porto Alegre: Fabris, 1987.

FILIZOLA, Paula. MEC E OAB assinam acordo para aprimorar cursos de direito. Ministério da Educação. Disponível em: http://portal.mec.gov.br/ultimas-noticias/212-educacao-superior1690610854/18533-mec-e-oab-assinam-acordo-para-aprimorar-cursos-de-direito. Acesso em: 31 jan. 2019.

GHIRARDI, José Garcez. et al (Coords.). Ensino Superior 2012 - Instituições: Cursos de Direito, Instituições de Ensino Superior, Mantenedoras e Grupos Educacionais. Observatório do Ensino do Direito. São Paulo, vol. 2, núm. 1, novembro de 2014.

JUNQUEIRA, Eliane Botelho. Faculdades de Direito ou Fábricas de Ilusões? Rio de Janeiro: Letra Capital, 1999.

KREIN, José Dari. As relações de trabalho na era do neoliberalismo no Brasil. São Paulo: LTr, 2013.

KRÜGER, Frederico Marcos. Evolução e adequação curricular do curso jurídico. Disponível em: http://www.ambito-juridico.com.br/site/index.php?n_link=revista_artigos_leitura\&artigo_ $\mathrm{id}=7196$. Acesso em: 31 jan. 2019.

MARTINEZ, Luciano. Curso de Direito do Trabalho: relações individuais, sindicais e coletivas do trabalho. São Paulo: Saraiva, 2016.

MARTÍNEZ, Sérgio Rodrigo. A evolução do ensino jurídico. Disponível em: http:// www.egov.ufsc.br/portal/sites/default/files/anexos/29074-29092-1-PB.pdf. Acesso em: 31 jan. 2019.

NOBRE, Marcos. Apontamentos sobre a pesquisa em Direito no Brasil. Disponível em: http://bibliotecadigital.fgv.br/dspace/bitstream/handle/10438/2779/Pesquisa_Direito_Cadernos_Direito_GV.pdf?sequence=1. Acesso em: 31 jan. 2019. 
Ordem dos Advogados do Brasil. Quadro de Advogados regulares e recadastrados. Disponível em: https://www.oab.org.br/institucionalconselhofederal/quadroadvogados. Acesso em: 31 jan. 2019.

OLIVEIRA, André Macedo de. Ensino Jurídico: Diálogo entre teoria e prática. Porto Alegre: Fabris, 2004.

OLIVEIRA, Isabela Fadul. et al. Negociações Coletivas e as condições de eficácia da nova Lei de Estágio no Brasil. Buenos Aires: Asociación Latinoamericana de Estudios del Trabajo, 2016.

RODRIGUES, Horácio Wanderlei. Diretrizes Curriculares Nacionais dos Cursos de Direito: análise do Parecer CNE/CES n. ${ }^{\circ}$ 635/2018. Educação e diversidade: por uma formação jurídica plural e democrática. Maringá: IDDM, 2018, p. 13-96.

RODRIGUES, Horácio Wanderlei. Estágio e Núcleo de Prática Jurídica: o que muda com a Resolução CNE/CES n. ${ }^{\circ}$ 3/2017. Ensino Jurídico no Brasil: 190 anos de história e desafios. Porto Alegre, OAB/RS, 2017, p. 725-753.

RODRIGUES, Horácio Wanderlei. Novo currículo mínimo dos cursos jurídicos. Revista dos Tribunais. São Paulo, 1995.

RODRIGUES, Horácio Wanderlei. Prática jurídica e estágio nos cursos de Direito. Educação jurídica. São Paulo: Saraiva, 2013. p. 215-227.

RODRIGUES, Horácio Wanderlei. Pensando o Ensino do Direito no Século XXI: diretrizes curriculares, projeto pedagógico e outras questões pertinentes. Florianópolis: Fundação Boiteux, 2005.

RODRIGUEZ, Alma Elena Rueda. Las prácticas profesionales y las pasantías desde la legislación comparada. Revista Latinoamericana de Derecho Social. Cidade do México, núm. 19, julho-dezembro de 2014.

SEGNINI, Liliana. Educação e Trabalho: uma relação tão necessária quanto insuficiente. São Paulo em Perspectiva. São Paulo, vol. 14, núm. 2, abril-junho de 2000.

SILVA, Elza Maria Tavares. Ensino de Direito no Brasil: Perspectivas históricas gerais. Disponível em: http://www.scielo.br/scielo.php?script=sci_arttext\&pid=S141385572000000100008. Acesso em: 31 jan. 2019.

SOUSA JÚNIOR, José Geraldo de. Ensino do Direito, Núcleos de Prática e de Assessoria Jurídica. Veredas do Direito. Belo Horizonte, vol. 3, núm. 6, julho-dezembro de 2006, p. 123-144.

VENÂNCIO FILHO, Alberto. Das arcadas ao bacharelismo, 150 anos de educação jurídica. São Paulo: Perspectiva, 1977.

UNIVERSIDADE FEDERAL DA BAHIA. Resolução no: 06/2012, de 10 de outubro de 2012. Revoga a Resolução 02/1999 e regulamenta as atividades de monitoria no âmbito dos cursos de graduação. Disponível em: https://www.ufba.br/sites/portal.ufba.br/files/Resolu\%C3\%A7 \%C3\%A30\%2006.2012_0.pdf. Acesso em: 31 jan. 2019.

Recebido em: 28 fev. 2019.

Aceito em: $1^{\circ}$ abr. 2020. 